\title{
28 Research Square \\ Comparison of Cyclic Fatigue Resistance of Five Heat Treated NiTi Rotary Systems in Single and Double Curved Canals.
}

\author{
Mohammad Al-Obaida \\ King Saud University \\ Khalid Merdad \\ King Abdulaziz University \\ Ali Alkhamis \\ Ministry of Health \\ Muneer Khan Mohammed \\ King Saud University \\ Rahaf Al-Obaida \\ Riyadh Elm University \\ Ebtissam Al-Madi ( $\nabla$ ealmadi@ksu.edu.sa ) \\ King Saud University
}

\section{Research Article}

Keywords: Cyclic Fatigue, HyFlex, Vortex, ProTaper Next, OneCurve, curved canal

Posted Date: July 21st, 2021

DOI: https://doi.org/10.21203/rs.3.rs-600840/v1

License: (c) (1) This work is licensed under a Creative Commons Attribution 4.0 International License. Read Full License 


\section{Abstract}

\section{Background}

The aim of this study was to compare cyclic fatigue resistance (CFR) and separation patterns during rotating movement of five heat-treated nickel titanium files in both single and double-curved canals.

\section{Methods}

CFR was compared between five groups of 24 files each: HyFlex ${ }^{\circledR}$ EDM, HyFlex ${ }^{\mathrm{TM}}$ CM, Vortex Blue ${ }^{\circledR}$, Protaper Next ${ }^{\circledR}$, and One Curve, by determining the time needed to fracture (TTF) and the number of cycles to failure (NCF) in a cyclic fatigue testing device with a single 5-mm radius of curvature (ROC) and $60^{\circ}$ angle, and a double curvature; coronal curvature ( $5 \mathrm{~mm} \mathrm{ROC}$ and $60^{\circ}$ angle) and apical curvature (2 $\mathrm{mm} \mathrm{ROC}$ and $70^{\circ}$ angle). The separation pattern was evaluated, and file fragment separated length were measured. One-way ANOVA and Tukey's post-hoc were used to compare statistical differences between the groups. Scanning Electron Microscope (SEM) was used to investigate the fracture sites.

\section{$\underline{\text { Results }}$}

HyFlex $^{\text {TM }}$ CM files displayed significantly higher CFR, followed by HyFlex ${ }^{\circledR}$ EDM and Vortex Blue ${ }^{\circledR}$ in single curvature canals, and Protaper Next ${ }^{\circledR}$ (PTN) in the double curvature canals, as observed by TFF and NCF. PTN group had the highest tendency for files to extrude apically after separation in both curvatures.

\section{$\underline{\text { Conclusion }}$}

HyFlex $^{\text {TM }} \mathrm{CM}$ instruments have superior resistance to cyclic flexural fatigue within single canals with single and double curvatures, followed by HyFlex ${ }^{\circledR}$ EDM and Vortex Blue ${ }^{\circledR}$ instruments. Protaper Next ${ }^{\circledR}$ files followed by One Curve had the highest tendency to extrude apically after separation

\section{Clinical relevance}

HyFlex ${ }^{\mathrm{TM}} \mathrm{CM}$ instruments showed the highest safety in preparing canals with single or double curvatures, considering CFR.

\section{Background}

Since their introduction into clinical practice, nickel-titanium (NiTi) rotary endodontic instruments have enhanced the effectiveness of endodontic treatment with respect to accuracy, reduction of apical foramen transportation, and procedural time [1]. Their properties of shape memory, super-elasticity, and resistance to corrosion have minimized procedural errors since their use [2]. Despite the apparent advantages and excellent mechanical properties of NiTi alloy, the possibility of sudden fractures as a result of torsional overloading or flexural fatigue remains a major concern in clinical practice $[1,3]$. Cyclic 
fatigue occurs when the instrument rotates within a curved root canal and is exposed to a large number of tension-compression strain cycles at the maximum curvature of the canal [1]. The reasons for this fracture include operator-related factors [4], variations in the root and canal anatomy [5], and factors related to endodontic instruments such as alloy composition, manufacturing methods, and crosssectional geometry $[6,7]$. To address the instrument-related factors, several manufacturers have developed special thermomechanical processing techniques for NiTi instruments that significantly improve fatigue resistance in comparison with conventional superelastic NiTi alloys [8-10].

HyFlex ${ }^{\text {TM }} \mathrm{CM}$ files (Coltene-Whaledent, Allstetten, Switzerland) are made from a new type of NiTi wire, namely controlled memory (CM) wire. It is manufactured by a unique process that controls the material's memory [11]. HyFlex® EDM files (Coltene-Whaledent) are fabricated using an electro-discharge machining (EDM) process [12]. Protaper Next ${ }^{\circledR}$ (Dentsply, Maillefer) was developed using the new M-Wire alloy. Its design features include variable tapers and an off-centered rectangular cross section [13]. Vortex Blue ${ }^{\circledR}$ rotary files (Dentsply, Tulsa Dental) process the NiTi wire in a manner claimed to reduce shape memory [14]. The One Curve (Micro-Mega) single-file NiTi system is manufactured from a C-wire by using a proprietary heat treatment that results in a controlled memory and a variable cross-section [15].

The aim of this investigation was to compare the cyclic fatigue resistance and mode of separation between five heat-treated nickel titanium files in rotating movement in single and double curved canals. The null hypothesis is that there is no difference between cyclic fatigue resistance between all files tested, while the alternate hypothesis is that there is a difference between cyclic fatigue between all files tested.

\section{Methods}

Five groups; HyFlex ${ }^{\circledR} \operatorname{EDM}^{\circledR}(\mathrm{EDM}), \operatorname{HyFlex}^{\mathrm{TM}} \mathrm{CM}^{\circledR}(\mathrm{CM})$, Vortex Blue ${ }^{\circledR}(\mathrm{VTB})$, Protaper Next ${ }^{\circledR}(\mathrm{PTN})$, and One Curve $(\mathrm{OC})$, were tested with a cyclic fatigue resistance device manufactured to test cyclic fatigue. A total of 120 files of all systems with the same tip size $(0.25 \mathrm{~mm})$ and length $(25 \mathrm{~mm})$ with different cross-sections were examined. Twenty-four files were used in each group, subdivided into 2 sub-groups of 12 files each, and their cyclic fatigue resistance was examined in single-curvature and double-curvature artificial canals. A total of 10 groups were tested as follows:

Groups EDM 25/ in a single-curvature canal $(n=12)$ and a double-curvature canal $(n=12)$.

Groups CM 25/04 in a single-curvature canal $(n=12)$ and a double-curvature canal (12).

Groups VTB 25/04 in a single-curvature canal $(n=12)$ and a double-curvature canal $(n=12)$.

Groups PTN 25/05 in a single-curvature canal $(n=12)$ and a double-curvature canal $(n=12)$.

Groups OC 25/06 in a single-curvature canal $(n=12)$ and a double-curvature canal $(n=12)$.

The device used for cyclic fatigue testing was designed and manufactured by the authors (Fig. 1), as described in Al-Obaida et al [16]. Each instrument was used according to the manufacturer's instructions 
and activated by using a 6:1 reduction Sirona handpiece that was powered by a torque-controlled electric motor (X-Smart Plus (Dentsply Maillefer, Ballaigues, Switzerland). The rpm was set based on the manufacturers' suggestion, which was $300 \mathrm{rpm}$ for PTN, $400 \mathrm{rpm}$ for EDM, and OC, and $500 \mathrm{rpm}$ for CM and VTB. Root canal cream (RC-Plus ${ }^{\circledR}$, MEDICEPT UK LTD) was used as a lubricant at room temperature, to minimize the friction of the files in the canal.

Every instrument was rotated until it fractured. The time to fracture (TTF), in seconds, was logged for all samples using Zeiss Loupes (4x power of magnification) by the same observer. Number of cycles to failure (NCF) were calculated by multiplying the number of rotations/cycles per minute by the TTF. The tendency of the separated file to extrude apically 'separation patterns' were compared between the groups, and the fragment length and diameter was measured. Fracture surface characteristics were examined in representative samples from all groups by using SEM at 300X.

SPSS 20.0 software (SPSS Inc., Chicago, IL, USA) was used for analysis. The cyclic fatigue values were evaluated by one-way ANOVA and Tukey's post-hoc test to establish statistical differences between the groups. Significance was established at the $95 \%$ confidence level.

\section{Results}

\section{Time to fracture}

The mean values and standard deviations for the TTF are presented in Table 1. In the singlecurvature artificial canal, the CM group showed a significantly higher mean TTF than all other groups $(\mathrm{P}<$ .05). The mean TTF in the EDM group was significantly higher than those in the remaining groups $(\mathrm{P}<$ $.05)$, and the VTB group was significantly higher than those in the PTN, and OC groups $(P<.05)$. No significant difference was observed among the PTN, and OC groups $(P>0.05)$.

In the artificial canal with double curvatures, the CM group showed the highest mean TTF, which was significantly higher than those in the PTN and OC groups $(P>0.05)$ but not significantly different from the values in the other groups.

\section{Number of cycles to failure}

Mean and standard deviation values for NCF are presented in Table 1. In the single-curvature artificial canal, the CM group showed a significantly higher mean NCF than all other groups $(P>0.05)$. The NCF values in the EDM and VTB groups were not significantly different from each other but were significantly higher than the values in the PTN, and OC groups $(P>0.05)$. There were no significant differences between the PTN, and OC groups.

For the artificial canals with double curvatures, the CM group showed the highest mean NCF, followed by the OC, VTB, and EDM groups. The CM group value was significantly higher than those in the PTN groups $(P<.05)$. No significant difference was found among the EDM, VTB, or OC groups. 
The mean Fragment length and diameter at level of separation are shown in table 2, while the minimum and maximum diameter of the fracture in the tested $\mathrm{NiTi}$ instruments in single and double curvatures are shown in Fig 2. The EDM group in the single canal curvature had the significantly higher fragment length than all other groups at $6.46 \mathrm{~mm}(p=0.00)$, while fragment lengths of all other file groups in the single canal (range from $1.42 \mathrm{~mm}$ to $1.92 \mathrm{~mm}$ ) and the double canal (range $4.29 \mathrm{~mm}$ to $4.71 \mathrm{~mm}$ ) were not significantly different within the canal curvatures. Accordingly, the diameter at the site of fracture in the EDM group in the single canal (0.71) significantly differed from all other groups $(p=0.00)$, while the EDM, PTN and OC in the single curvature did not differ from one another $(0.36,0.37)$, nor did the CM and VTB in the single curvature $(0.42,0.43)$ differ from one another. Neither did the CM and VTB diameter at fracture site in the double canal $(0.32)$ differ from each other, nor did the PRN and OC $(0.52,0.53)$ in the single canal curvature. PTN group was the highest file with tendency to extrude apically after separation in single curvature canals and double curvature canals (12 and 11 out of 12 respectfully), followed by OC in both single and double curvature (11 and 7 out of 12 respectfully), then VTB in double curvature $(2 / 12)$. EDM,$C M$ in both curvatures and VTB in single curvature did not have tendency to extrude after separation.

\section{$\underline{\text { SEM Evaluation }}$}

The fractographic analysis of the specimens' fracture surface exhibited fatigue crack initiation at two distinct regions. Fatigue striations were observed in (region a) and a dimpled surface (region b) as shown in the Fig $3,4$.

\section{Discussion}

Several thermo-mechanical processing and manufacturing techniques have been developed to optimize the microstructure of NiTi alloys and provide superior mechanical properties to the instruments $[3,17]$. Thermal treatment may significantly increase the fatigue resistance of NiTi files [18]; the heat treatments change the crystalline disposition of the nickel and titanium atoms, which undergo a main shift from the cubic (austenitic) to tetragonal molecular arrangement (martensitic) phase, inducing different mechanical properties [17, 19-22]. In the present study, five novel heat-treated NiTi files were compared with respect to their cyclic fatigue resistance and separation patterns in single and double curved canals. The main finding of our study was that $\mathrm{CM}$ files displayed significantly higher cyclic fatigue resistance in an S-shaped artificial canal, denying the null hypothesis is that there is no difference between cyclic fatigue resistance between all files tested.

Teeth with S-shaped (double curvatures) root canals can be challenging, since the instruments can be vulnerable to deviations in anatomy, loss of working length, and potential for file separation. Fatigue has been implicated to be the main reason for the fracture of clinically used endodontic files [23]. Other studies have tested cyclic fatigue in various instruments in vitro in double curvatures [24], however in the present study, two artificial canals (single and double curvatures) were specially manufactured and their cross-sectional measurements were designed to be suitable for all systems to minimize any factors that 
may affect the results. Extracted teeth were not used, since imitating clinical conditions and ensuring standardization is difficult with extracted teeth [25]. Nevertheless, the artificial canal has greater volume in comparison to the instruments which allow then to rotate with no low contact area, which is considered a limitation in all studies of this nature but do provide important initial information in file testing.

Fatigue resistance was compared using the TTF and NCF values. In both single- and double-curvature canals, TTF was the longest for CM, followed by EDM, VTB, PTN, and finally OC. CM's TTF was almost double the TTF for EDM and 7 times higher than the lowest values (PTN and OC). CM also showed the highest NCF in the single-curvature assessments and double-curvature assessments. Controlled memory (CM) wire is produced by a special thermo-mechanical process involving the alloy that controls the memory of the material, making the files extremely flexible but without the shape memory, in contrast to conventional NiTi instruments. This imparts high fatigue resistance to the CM [14, 26], allowing it to easily bend during use and recover its original shape when heated above the transformation temperature [27]. Our present results agree with many studies that have demonstrated that CM wire instruments have greater cyclic fatigue resistance than conventional NiTi instruments $[14,26,28,29]$. However, the standard deviation for the TTF in the CM group was very high. CM showed similar numbers in the doublecurve canal, while the numbers differed in the single-curve canal. This could be due to a manufacturer's defect in one batch of the files, or it may indicate that despite the high resistance to fracture in this type of file, its reliability is questionable. It is important to note that all tests were performed by the same operator, and all other standard deviations were low, indicating that the possibility of experimenter error is low.

EDM are also produced with CM wire; however, they are produced with a different fabrication process that uses an electro-discharge machining (EDM) process [12]. In the EDM process, melting and evaporation of the top layer creates a rough, crater-like surface finishing $[12,30]$. EDM files are the first endodontic instruments manufactured with this process. The surfaces created through the EDM process could improve the cutting efficiency of tools, as compared to conventional NiTi endodontic files [31]. However, some studies have reported that this surface finish has an effect on the crack initiation process [32] and structural irregularities of the instrument surface may compromise its integrity during clinical use, making the files more susceptible to fracture [7], while others have shown that the cyclic fatigue associated with EDM was significantly greater than that for the conventionally manufactured CM files [20]. In the present study, EDM files showed better resistance to cyclic fatigue than the other files, which is in agreement with the findings of several studies [12, 33, 34], but its resistance was still lower than that of the CM files, which is inconsistent with other findings [35]. On the other hand, the EDM file showed a significantly longer fractured fragment length and separated at a larger diameter than all other files in both single and double canal curvatures. This supports the theory of compromised integrity due to instrument irregularities. Both files showed a reduced tendency to extrude out of the canal once fractured, which might prove to be an important consideration in cases of roots with open apexes or enlarged apexes due to resorption or presence of a periapical lesion. 
A smaller taper and metal mass of the instrument are known to induce better cyclic fatigue resistance [12, 36-38]. Therefore, the NiTi files that were chosen for this study had comparable taper and size and were used for a single file canal preparation. These systems use a reciprocating motion and claim to shape root canals with a single file [39], which amounts to shorter working time; shorter learning curve, and a reduction in the number of instruments needed [2]. However, single-shaping files are exposed to high levels of stress, which might lead to cyclic and torsional fatigue [40]. Therefore, files used in single-file canal preparation systems should have a high resistance to fracture. In addition, cyclic flexural fatigue resistance decreases with extended use, which might be the case if these files are used for single use [41].

A lubricant was used to reduce friction during the test, as its importance was established in a pilot study and other studies [42]. Although current studies have shown that temperature was found to significantly increase the cyclic fatigue of nickel-titanium rotary files, and reduce the NCF, suggesting that cyclic fatigue studies should be conducted at body temperature (Dosanjh et al. 2017; Klymus et al. 2019), our studies were conducted at room temperature for initial testing.

In order to study the failure mechanism of the test files, the cross-sections of the broken files were viewed under the SEM. Although, 3D replicas could be used to compare cyclic fatigue among files with duplicated reconstructed anatomy, the SEM provides important information regarding fatigue failure within the instruments, which is the reason behind the current real-life replica testing apparatus. EDM showed the highest difference between the diameter of fracture in single and double curvature, the highest being in the single curvature, while the smallest difference was in the VTB, and CM files. The analysis revealed fatigue failure of the test files with crack initiation at one or more points. All files exhibited two distinct regions, one with the fatigue striations (region a) and the other with the dimpled surface (region b) as shown in Fig. $(3,4)$. The fatigue striations are the characteristic feature of fatigue crack growth whereas the dimpled surface indicate ductile facture. The crack originates at the edge due to the presence of high stresses as shown in Fig. $(3 a, 4 a)$ and it propagates until the fatigue striations. Micro-voids coalescence takes place by the nucleation of micro-voids, which results in weakening of the material, after that ductile fracture occurs until the failure that is evident from the dimpled surface as seen in Fig. (3b, 4b).

\section{Conclusion}

Within the limitations of this study, HyFlex ${ }^{\mathrm{TM}} \mathrm{CM}$ instruments displayed significantly higher cyclic fatigue resistance and therefore, superior fracture resistance, than HyFlex ${ }^{\circledR}$ EDM and Vortex Blue ${ }^{\circledR}$ within single canals with single and double curvatures. ProTaper $\mathrm{Next}{ }^{\circledR}$, and One Curve showed less resistance to cyclic fatigue in the tested canals. Additionally, Protaper Next ${ }^{\circledR}$ files followed by One Curve had the highest tendency to extrude apically after separation, especially in single curve canals, while HyFlex ${ }^{\circledR}$ EDM and HyFlex ${ }^{\text {TM }} \mathrm{CM}$ did not have any tendency to extrude.

\section{Abbreviations}


CFR; Cyclic Fatigue Resistance

TTF; Time needed To Fracture

NCF; Number of Cycles to Failure

ROC; Radius Of Curvature

$\mathrm{CM}$; Controlled Memory wire

EDM; Electro-Discharge Machining process

EDM; HyFlex® EDM ${ }^{\circledR}$

CM; HyFlex ${ }^{\text {TM }}$ CM ${ }^{\circledR}$

VTB; Vortex Blue ${ }^{\circledR}$

PTN; Protaper Next ${ }^{\circledR}$

OC; One Curve

\section{Declarations}

\section{Ethics approval and consent to participate}

Not applicable

Consent for publication

Not applicable

\section{Availability of data and materials}

The datasets used and/or analyzed during the current study are available from the corresponding author on reasonable request.

\section{Competing interests}

The datasets used and/or analysed during the current study are available from the corresponding author on reasonable request.

\section{Funding}

There was no funding for this research

\section{Authors' contributions}


MO \& AK devised the concept. AK \& MKM ran the tests and collected the data. MO \& EM made the analysis. RO \& EM drafted the manuscript. All authors revised the manuscript.

\section{Acknowledgements}

Not applicable

\section{References}

1. Parashos, P. and H.H. Messer, Rotary NiTi instrument fracture and its consequences. Journal of endodontics, 2006. 32(11): p. 1031-1043.

2. Arens, F.C., et al., Evaluation of single-use rotary nickel-titanium instruments. Journal of Endodontics, 2003. 29(10): p. 664-666.

3. Iqbal, M.K., M.R. Kohli, and J.S. Kim, A retrospective clinical study of incidence of root canal instrument separation in an endodontics graduate program: a PennEndo database study. Journal of endodontics, 2006. 32(11): p. 1048-1052.

4. Parashos, P., I. Gordon, and H.H. Messer, Factors influencing defects of rotary nickel-titanium endodontic instruments after clinical use. Journal of Endodontics, 2004. 30(10): p. 722-725.

5. Di Fiore, P.M., A dozen ways to prevent nickel-titanium rotary instrument fracture. The Journal of the American Dental Association, 2007. 138(2): p. 196-201.

6. Kim, T., et al., Stress distribution of three NiTi rotary files under bending and torsional conditions using a mathematic analysis. International Endodontic Journal, 2009. 42(1): p. 14-21.

7. Kim, H.-C., et al., Cyclic fatigue and fracture characteristics of ground and twisted nickel-titanium rotary files. Journal of endodontics, 2010. 36(1): p. 147-152.

8. Gambarini, G., et al., Fatigue resistance of engine-driven rotary nickel-titanium instruments produced by new manufacturing methods. Journal of endodontics, 2008. 34(8): p. 1003-1005.

9. Johnson, E., et al., Comparison between a novel nickel-titanium alloy and 508 nitinol on the cyclic fatigue life of ProFile 25/. 04 rotary instruments. Journal of endodontics, 2008. 34(11): p. 14061409.

10. Hieawy, A., et al., Phase transformation behavior and resistance to bending and cyclic fatigue of ProTaper Gold and ProTaper Universal instruments. Journal of endodontics, 2015. 41(7): p. 11341138.

11. Seago, S.T., et al., Effect of repeated simulated clinical use and sterilization on the cutting efficiency and flexibility of Hyflex CM nickel-titanium rotary files. Journal of endodontics, 2015. 41(5): p. 725728.

12. Pedullà, E., et al., Torsional and cyclic fatigue resistance of a new nickel-titanium instrument manufactured by electrical discharge machining. Journal of endodontics, 2016. 42(1): p. 156-159.

13. Pérez-Higueras, J.J., et al., Differences in cyclic fatigue resistance between ProTaper Next and ProTaper Universal instruments at different levels. Journal of endodontics, 2014. 40(9): p. 1477- 
1481.

14. Plotino, G., et al., Blue treatment enhances cyclic fatigue resistance of vortex nickel-titanium rotary files. Journal of endodontics, 2014. 40(9): p. 1451-1453.

15. Topçuoğlu, H., et al., Laboratory comparison of cyclic fatigue resistance of WaveOne Gold, Reciproc and WaveOne files in canals with a double curvature. International endodontic journal, 2017. 50(7): p. 713-717.

16. Al-Obaida, M.I., et al., Comparison of cyclic fatigue resistance of 5 heat-treated nickel-titanium reciprocating systems in canals with single and double curvatures. Journal of endodontics, 2019. 45(10): p. 1237-1241.

17. Shen, Y., et al., Current challenges and concepts of the thermomechanical treatment of nickeltitanium instruments. Journal of endodontics, 2013. 39(2): p. 163-172.

18. Zinelis, S., et al., The effect of thermal treatment on the resistance of nickel-titanium rotary files in cyclic fatigue. Oral Surgery, Oral Medicine, Oral Pathology, Oral Radiology, and Endodontology, 2007. 103(6): p. 843-847.

19. Gao, Y., et al., Evaluation of the impact of raw materials on the fatigue and mechanical properties of ProFile Vortex rotary instruments. Journal of endodontics, 2012. 38(3): p. 398-401.

20. Pirani, C., et al., HyFlex EDM: superficial features, metallurgical analysis and fatigue resistance of innovative electro discharge machined NiTi rotary instruments. International endodontic journal, 2016. 49(5): p. 483-493.

21. Drexel, M., G. Selvaduray, and A. Pelton. The effects of cold work and heat treatment on the properties of nitinol wire. in ASME 2007 2nd Frontiers in Biomedical Devices Conference. 2007. American Society of Mechanical Engineers.

22. Iacono, F., et al., Structural analysis of HyFlex EDM instruments. International endodontic journal, 2017. 50(3): p. 303-313.

23. Sattapan, B., et al., Defects in rotary nickel-titanium files after clinical use. Journal of endodontics, 2000. 26(3): p. 161-165.

24. Al-Sudani, D., et al., Cyclic fatigue of nickel-titanium rotary instruments in a double (S-shaped) simulated curvature. Journal of endodontics, 2012. 38(7): p. 987-989.

25. Yao, J.H., S.A. Schwartz, and T.J. Beeson, Cyclic fatigue of three types of rotary nickel-titanium files in a dynamic model. Journal of endodontics, 2006. 32(1): p. 55-57.

26. Shen, Y., et al., Fatigue testing of controlled memory wire nickel-titanium rotary instruments. Journal of endodontics, 2011. 37(7): p. 997-1001.

27. Davis, J.R., Nickel, cobalt, and their alloys. 2000: ASM international.

28. Shen, Y., et al., Effect of environment on fatigue failure of controlled memory wire nickel-titanium rotary instruments. Journal of endodontics, 2012. 38(3): p. 376-380.

29. Capar, I.D., et al., Comparison of the cyclic fatigue resistance of 5 different rotary pathfinding instruments made of conventional nickel-titanium wire, M-wire, and controlled memory wire. Journal 
of endodontics, 2015. 41(4): p. 535-538.

30. Theisen, W. and A. Schuermann, Electro discharge machining of nickel-titanium shape memory alloys. Materials Science and Engineering: A, 2004. 378(1-2): p. 200-204.

31. Payal, H., R. Choudhary, and S. Singh, Analysis of electro discharge machined surfaces of EN-31 tool steel. 2008.

32. Cheung, G. and B. Darvell, Fatigue testing of a NiTi rotary instrument. Part 2: fractographic analysis. International endodontic journal, 2007. 40(8): p. 619-625.

33. Gündoğar, M. and T. Özyürek, Cyclic fatigue resistance of OneShape, HyFlex EDM, WaveOne gold, and Reciproc blue nickel-titanium instruments. Journal of endodontics, 2017. 43(7): p. 1192-1196.

34. Uslu, G., et al., Cyclic fatigue resistance of R-Pilot, HyFlex EDM and PathFile nickel-titanium glide path files in artificial canals with double (S-shaped) curvature. International endodontic journal, 2018. 51(5): p. 584-589.

35. Furlan, R.D., Comparison of mechanical behavior between conventional NiTi, CM, M-Wire and CMEDM alloy instruments for cyclic fatigue and torsion fracture-evaluation of fracture surface in scanning electron microscope. Universidade de São Paulo.

36. Grande, N., et al., Cyclic fatigue resistance and three-dimensional analysis of instruments from two nickel-titanium rotary systems. International Endodontic Journal, 2006. 39(10): p. 755-763.

37. Kaval, M.E., et al., Comparative evaluation of cyclic fatigue resistance of four different nickeltitanium rotary files with different cross-sectional designs and alloy properties. Clinical oral investigations, 2017. 21(5): p. 1527-1530.

38. Plotino, G., et al., A review of cyclic fatigue testing of nickel-titanium rotary instruments. Journal of endodontics, 2009. 35(11): p. 1469-1476.

39. Kim, H.-C., et al., Cyclic fatigue and torsional resistance of two new nickel-titanium instruments used in reciprocation motion: Reciproc versus WaveOne. Journal of endodontics, 2012. 38(4): p. 541-544.

40. Yared, G., Canal preparation using only one Ni-Ti rotary instrument: preliminary observations. International endodontic journal, 2008. 41(4): p. 339-344.

41. Tewari, R.K., et al., Fracture of rotary nickel titanium instruments. Journal of Oral Research and Review, 2017. 9(1): p. 37.

42. Tripi, T.R., A. Bonaccorso, and G.G. Condorelli, Cyclic fatigue of different nickel-titanium endodontic rotary instruments. Oral Surgery, Oral Medicine, Oral Pathology, Oral Radiology, and Endodontology, 2006. 102(4): p. e106-e114.

\section{Tables}

Table 1: Mean and standard deviation of time to fracture (TTF) and number of cycles to failure (NCF) in the tested NiTi instruments 


\begin{tabular}{|c|c|c|c|c|c|c|}
\hline Groups & & (n) & $\begin{array}{l}\text { Mean } \\
\text { TTF }\end{array}$ & $\begin{array}{l}\text { Std. } \\
\text { Deviation }\end{array}$ & Mean NCF & $\begin{array}{l}\text { Std. } \\
\text { Deviation }\end{array}$ \\
\hline \multirow{5}{*}{$\begin{array}{l}\text { Single Canal } \\
\text { Curvature } \\
60 \text { R } 50\end{array}$} & HyFlex® EDM & 12 & 258.92 & 67.67 & $103,566.67$ & 27069.45 \\
\hline & HyFlex $^{\text {TM }} \mathrm{CM}$ & 12 & 451.00 & 114.72 & $225,500.00$ & 57359.31 \\
\hline & Vortex Blue ${ }^{\circledR}$ & 12 & 167.75 & 17.70 & $83,875.00$ & 8847.51 \\
\hline & $\begin{array}{l}\text { Pro Taper } \\
\text { Next } \AA\end{array}$ & 12 & 63.75 & 7.56 & $19,125.00$ & 2267.21 \\
\hline & One Curve & 12 & 95.53 & 8.74 & $38,133.33$ & 3496.84 \\
\hline \multirow{5}{*}{$\begin{array}{l}\text { Double Canal } \\
\text { Curvature } \\
\text { S curve }\end{array}$} & HyFlex ${ }^{\circledR}$ EDM & 12 & 73.17 & 22.54 & $29,266.67$ & 9016.89 \\
\hline & HyFlex $^{\text {TM }} \mathrm{CM}$ & 12 & 107.83 & 26.35 & $53,916.67$ & 12173.38 \\
\hline & Vortex Blue ${ }^{\circledR}$ & 12 & 60.42 & 18.40 & $30,208.33$ & 9198.46 \\
\hline & $\begin{array}{l}\text { Pro Taper } \\
\text { Next }{ }^{\circledR}\end{array}$ & 12 & 37.74 & 6.62 & $11,325.00$ & 1986.37 \\
\hline & One Curve & 12 & 76.25 & 17.38 & $30,500.00$ & 6951.52 \\
\hline
\end{tabular}

Table 2: Mean Fragment length and diameter at level of separation in the tested NiTi instruments 


\begin{tabular}{|c|c|c|c|c|c|c|}
\hline \multicolumn{2}{|l|}{ Groups } & (n) & $\begin{array}{l}\text { Mean Fragment } \\
\text { length }(\mathrm{mm})\end{array}$ & $\begin{array}{l}\text { Std. } \\
\text { Deviation }\end{array}$ & $\begin{array}{l}\text { Mean Fragment } \\
\text { diameter }(\mathrm{mm})\end{array}$ & $\begin{array}{l}\text { Std. } \\
\text { Deviation }\end{array}$ \\
\hline $\begin{array}{l}\text { Single Canal } \\
\text { Curvature }\end{array}$ & $\begin{array}{l}\text { HyFlex® } \\
\text { EDM }\end{array}$ & 12 & 6.46 & 0.58 & 0.71 & 0.02 \\
\hline \multirow[t]{4}{*}{$60 \mathrm{R} 50$} & $\begin{array}{l}\text { HyFlex } \\
\text { CM }\end{array}$ & 12 & 4.29 & 0.66 & 0.42 & 0.03 \\
\hline & $\begin{array}{l}\text { Vortex } \\
\text { Blue® }\end{array}$ & 12 & 4.58 & 1.00 & 0.43 & 0.04 \\
\hline & $\begin{array}{l}\text { Pro Taper } \\
\text { Next }{ }^{\circledR}\end{array}$ & 12 & 4.50 & 0.71 & 0.52 & 0.04 \\
\hline & One Curve & 12 & 4.71 & 0.33 & 0.53 & 0.02 \\
\hline $\begin{array}{l}\text { Double Canal } \\
\text { Curvature }\end{array}$ & $\begin{array}{l}\text { HyFlex® } \\
\text { EDM }\end{array}$ & 12 & 1.42 & 0.29 & 0.36 & 0.02 \\
\hline \multirow[t]{4}{*}{ S curve } & $\begin{array}{l}\text { HyFlex }{ }^{\mathrm{TM}} \\
\mathrm{CM}\end{array}$ & 12 & 1.71 & 0.33 & 0.32 & 0.01 \\
\hline & $\begin{array}{l}\text { Vortex } \\
\text { Blue® }\end{array}$ & 12 & 1.63 & 0.23 & 0.32 & 0.01 \\
\hline & $\begin{array}{l}\text { Pro Taper } \\
\text { Next } \AA\end{array}$ & 12 & 1.92 & 0.29 & 0.37 & 0.02 \\
\hline & $\begin{array}{l}\text { One } \\
\text { Curve }\end{array}$ & 12 & 1.79 & 0.40 & 0.36 & 0.02 \\
\hline
\end{tabular}

Figures 


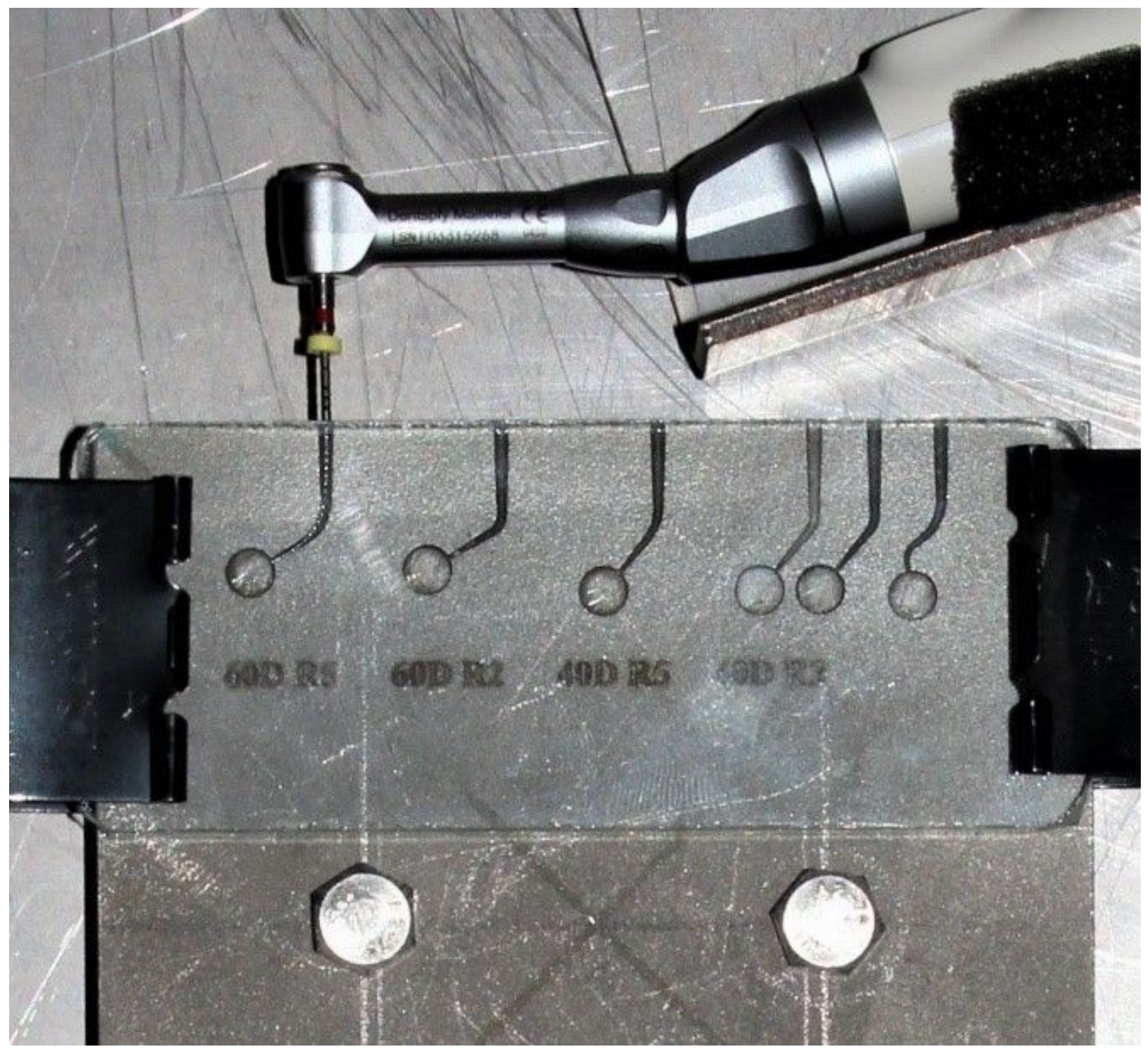

Figure 1

Cyclic Fatigue Testing Device 


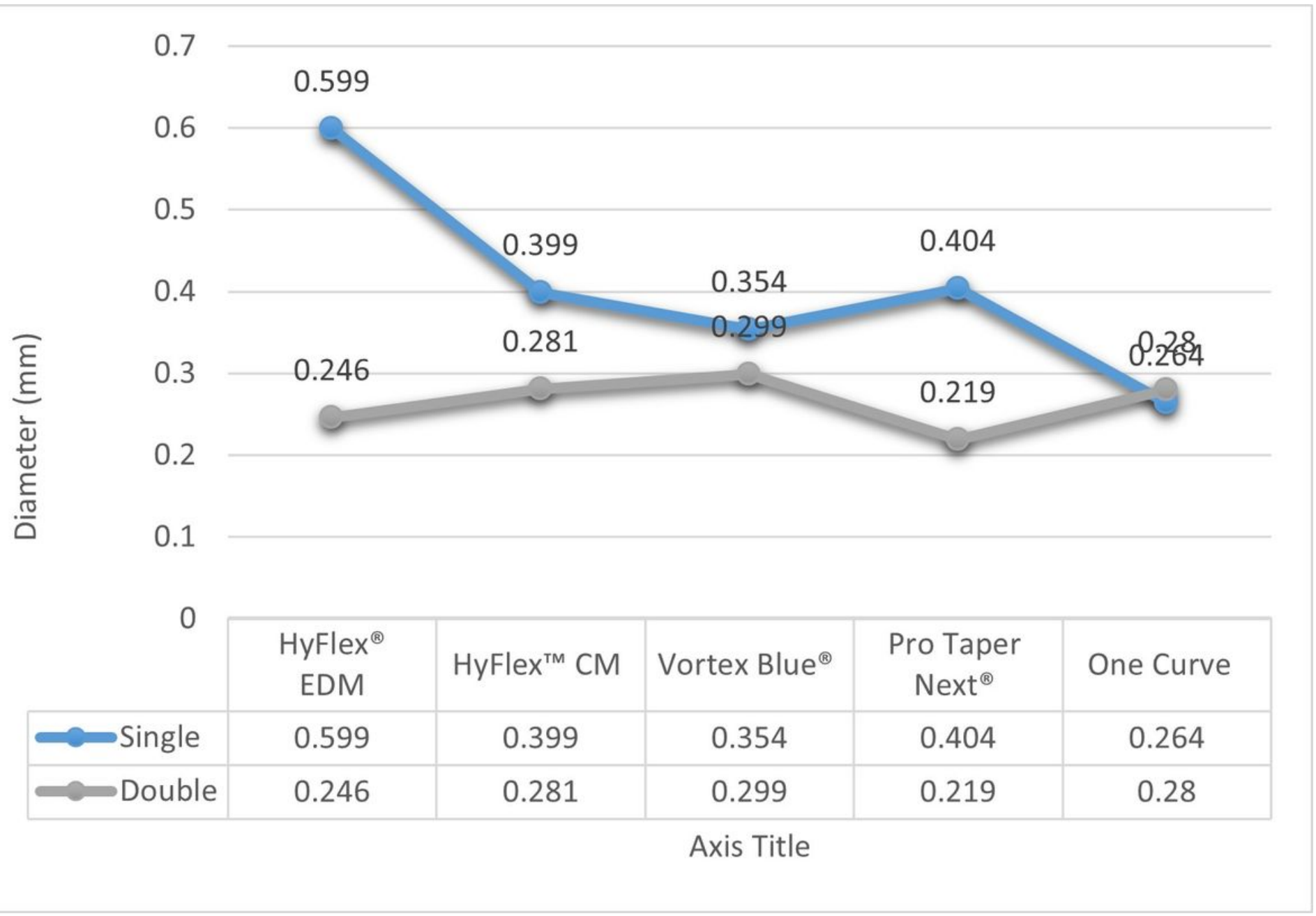

Figure 2

Minimum and Maximum diameter of fracture in the tested NiTi instruments in single and double curvatures. 


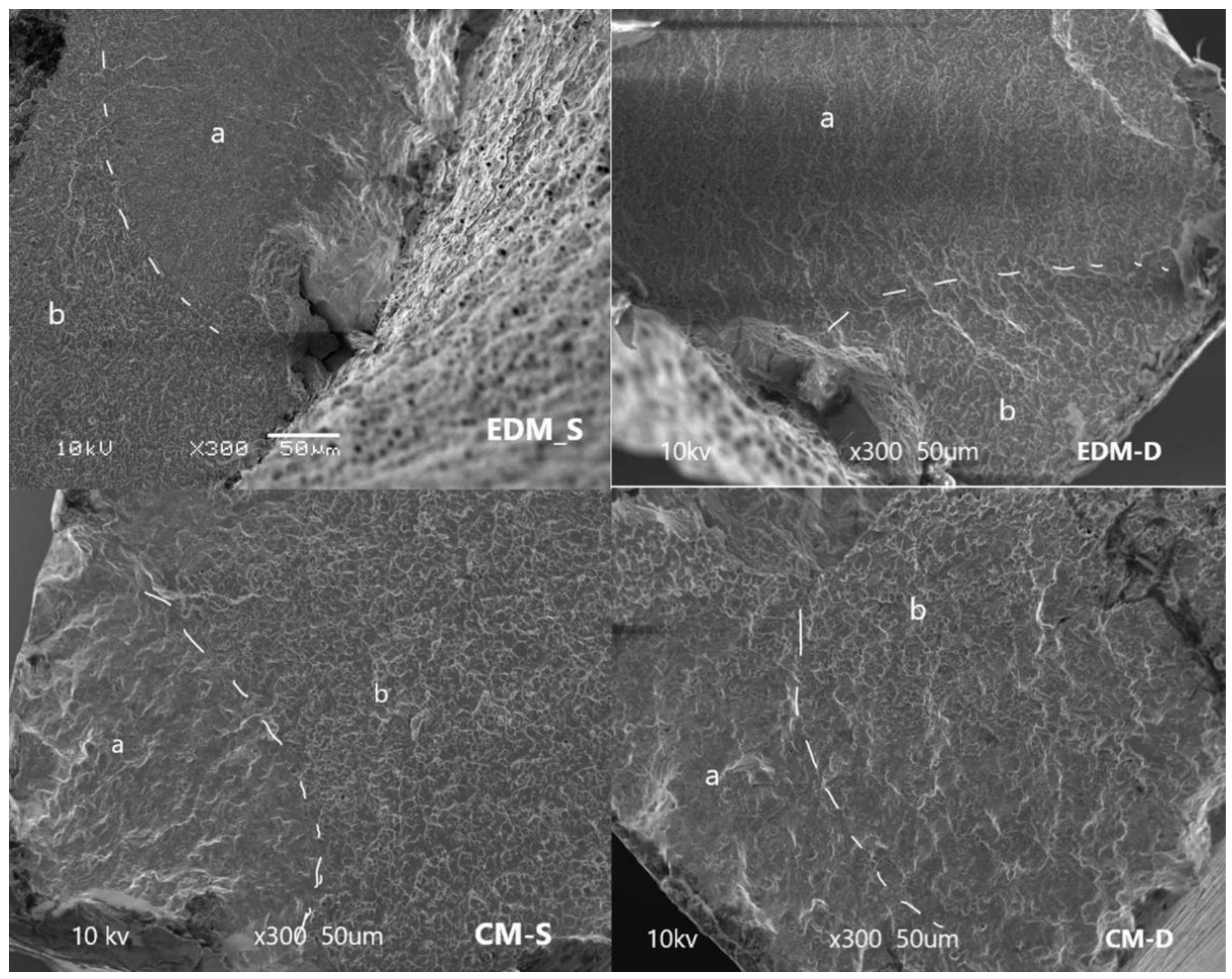

Figure 3

Micro-voids and fracture showing fatigue striations (a) and dimpled surface (b) in EDM Single Canal, EDM Double canal, CM Single canal, and CM Double canal. 


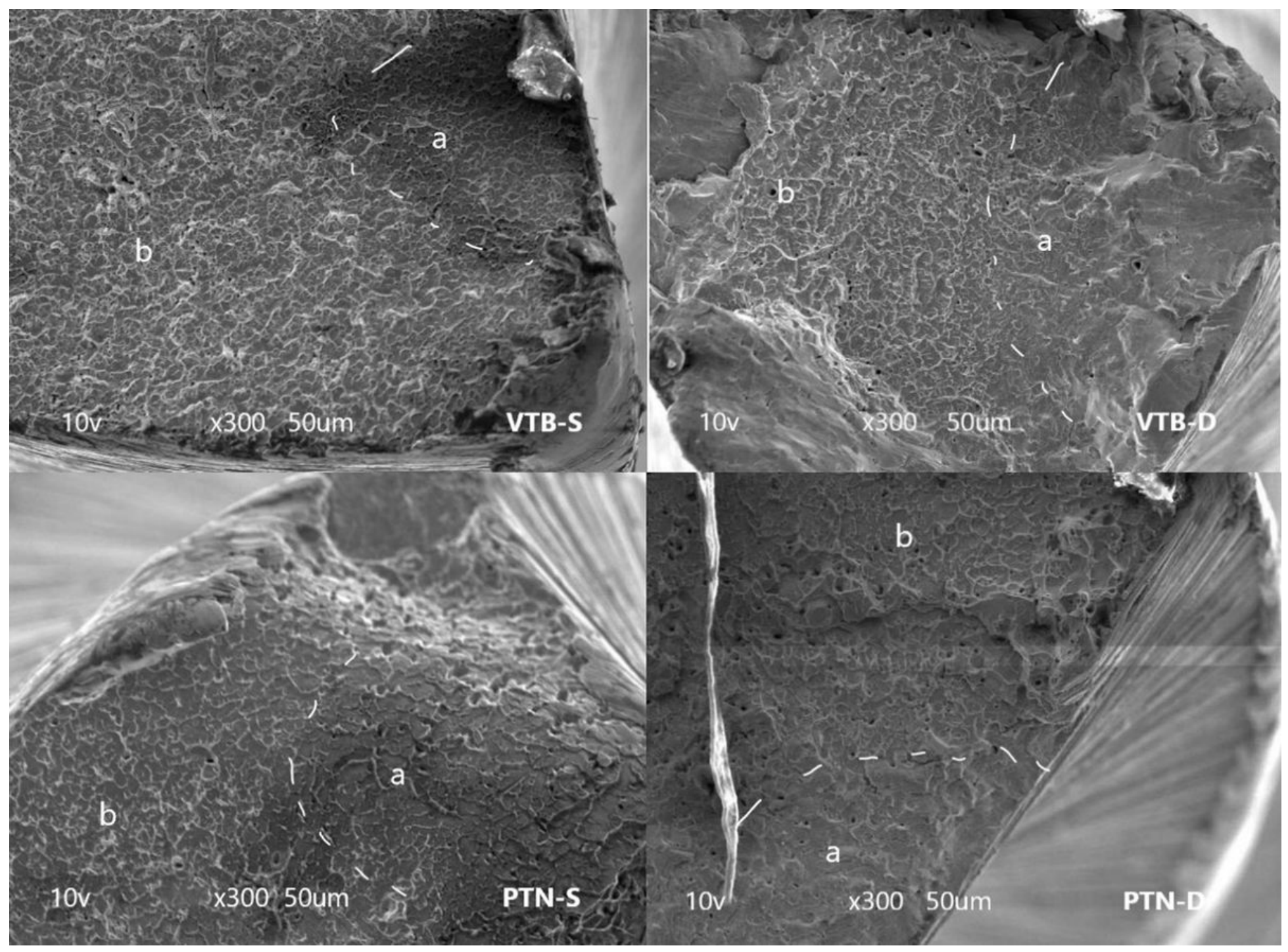

Figure 4

Micro-voids and fracture showing fatigue striations (a) and dimpled surface (b) in VTB Single Canal, VTB Double canal, PTM Single canal, and PTM Double canal. 